40

\section{Guidelines for Identifying Catastrophe Victims for Evacuations in the Field}

Fonrouge $J M,{ }^{*}$ Fonrouge $G,{ }^{* *}$ Belanger $M$, *** Sabathie $M^{+}$

* Universite de Bordeaux I, SAMU 71, MD, DEA,

Centre Hospitalier

Chalon S/Saone, France

** Universite de Bordeaux I

*** Universite de Bordeaux I

+ Universite de Bordeaux II

Chalon S/Saone, France

The concept of evacuating comatose victims may be valid in catastrophic situations, particularly when fire is involved. Burn patients may be seriously injured, disfigured by edema, comatose, and requiring care in a specialized hospital unit in a neighboring country.

Such an arrangement operates in peacetime, but for medical means to be used pragmatically and appropriately, it would be better to develop initial identification files to be used in association with medical examination results and techniques from the patient's previous follow-up. Therefore, each emergency unit should have a free hand to intervene, and should have at its disposal both identification and evacuation files.

Such files (of which an example is proposed) must meet three objectives:

1) enable simple, rapid comparable identification;

2) allow comparison with information supplied by teams investigating close families and structures possessing useful information, such as dental records, blood transfusion units, genetic data banks, etc.); and

3) enable follow-up of this identification by the medical unit receiving the patient, with the assistance of complementary data.

Therefore, it is necessary for emergency services coordinating on-site evacuation and those in the receiving hospital to be organized when handling evacuation abroad. Such organization requires the following elements:

1) initial training in identification data for all physicians who might be first on-site at a catastrophe; and

2) coordination with the forensic physicians of other countries who may be able to offer assistance.

This may be at the moment of the catastrophe if the time of intervention allows, or in the receiving country in association with the intensive care unit. Under such conditions, it would be reasonable to conceive of the crossing of borders by unidentified patients when major catastrophes have occurred.
41

\section{Preparedness for Mass-Casualty Incidents in Multiple Locations: International Car Rallying in Western Australia}

Dann L

Chief Medical Officer, Rally Australia

Department of Emergency Medicine

Sir Charles Gairdner Hospital

Nedlands, West Australia, Australia

Object: To describe the problems associated with the provision of trauma services across a sparsely populated area and at multiple sites.

Overview: International, automobile rallying has been a feature of Western Australia for five years. Rally Australia takes place over four days in September (the southern hemisphere winter), with 32 Special Stages at distances up to $200 \mathrm{~km}$ from the capital city, Perth. West Australia, a state of about 1-millionsquare miles, has a population of 1.6 million most of whom live within $50 \mathrm{~km}$ ( 31.5 miles) of Perth.

This paper illustrates some of the difficulties in planning and providing mass-casualty management at multiple sites outside of the metropolitan area, where services are reduced and transportation is difficult.

\section{2 \\ Cooperation of Hungarian Civil and Military Health Services in Disaster Relief \\ Farkas J \\ Central Military Hospital \\ Budapest, Hungary}

This is a short summary of the current disaster relief system of Hungary, a middle European country of 10-million inhabitants residing in a territory of 93,032 square kilometers.

The disaster plans of civil health institutions and hospitals are coordinated with those of five military hospitals and the plans of Hungarian Civil Defense, National Ambulance, and Fire-Guard services for disaster preparedness. Training is provided through education programs consisting of graduate and post-graduate courses for physicians, nursing staff, and volunteers. Joint training is provided for military and civilian staff. Research includes a focus on equipment that is critical to definitive management of the injured on the scene and when hospitalized.

Military and Disaster Medicine recently has been accepted in Hungary as a specialty in its own right. 